\title{
THE CAUSE OF REDUCED GROWTH OF MANDUCA SEXTA LARVAE ON A LOW-WATER DIET: INCREASED METABOLIC PROCESSING COSTS OR NUTRIENT LIMITATION?
}

\author{
Michael M. Martin and Heidi M. Van't Hof \\ Department of Biology, University of Michigan, Ann Arbor, MI 48109, U.S.A.
}

(Received 28 July 1987; revised 9 November 1987)

\begin{abstract}
Relative growth rates and nitrogen accumulation rates are lower for third-instar Manduca sexta larvae on an artificial diet containing $65 \%$ water than on one containing $82 \%$ water, due to reduced efficiencies of conversion of digested food and digested nitrogen into larval biomass. Uric acid production is 2.0-2.5-fold greater, and non-feeding respiration rates $16.0 \%$ higher in the larvae on the low-water diet. Food is the major source of water for the larvae, with metabolic water making only a minor contribution to water input. Faecal excretion is the major avenue of water loss, although a significant amount of water is also lost by transpiration. Larvae from the low-water diet retain and use a higher percentage of the water they gain than larvae from the high-water diet $(49.4 \%$ vs $41.9 \%)$. They produce much drier faeces $(48.1 \%$ water vs $77.3 \%$ water), and, because their tissues are less hydrated ( $81.3 \%$ water vs $88.1 \%$ water), they synthesize $70 \%$ more new, fully hydrated tissue from a given amount of water than larvae from the high-water diet. We discuss problems involved in the use of determinations of efficiency of conversion of digested food in establishing causal links between diet, growth, and metabolic maintenance costs, and also offer a definition of food processing costs that distinguishes them from metabolic costs attributable to other processes, such as food acquisition, growth, and moulting. We conclude that reduced growth and reduced efficiency of conversion of digested food on low-water diets are due to limitation in the amount of water available for the synthesis of new hydrated tissue, and not to the imposition of higher food processing costs.
\end{abstract}

Key Word Index: Tobacco hornworm, Manduca sexta, growth, nutritional indices, food utilization, nitrogen budget, water budget, uric acid production, respiration rates, metabolic maintenance costs, food processing costs

\section{INTRODUCTION}

The growth rates of herbivorous lepidopteran larvae are strongly dependent upon the water content of their food (Scriber, 1977; Reese and Beck, 1978; Scriber and Feeny, 1979; Timmins et al., 1987). Significantly reduced larval growth rates on diets low in water are due primarily to reduced efficiencies of converting assimilated material into larval biomass rather than to reduced consumption rates or reduced assimilation efficiencies. Since efficiency of conversion of digested food reflects the allocation of assimilated food to growth vis à vis energy metabolism, the lower values of this efficiency have been interpreted as an indication of higher metabolic maintenance costs for larvae on a low-water diet (Slansky and Scriber, 1985). Although this interpretation is a valid application of the Laws of Conservation of Energy and Conservation of Mass to the larval energy budget, a number of unwarranted interpretations of causal links between diet and growth, formulated within the context of an analysis of the energy and mass budgets of larval growth, have begun to appear regularly in the literature of nutritional ecology. For example. it is often implied that a high metabolic maintenance cost, inferred from a low efficiency of conversion of digested food, must be the cause of a low growth rate. The assumption underlying this interpretation is that growth is carbon-limited, in which case any carbon allocated to energy metabolism is not available for the production of new tissue. However, when growth is not carbon-limited, a high metabolic maintenance cost could be the consequence, rather than the cause, of a low growth rate. For example, if water were growth-limiting then other potentially useful nutrients assimilated from the diet would be present in amounts exceeding those that could be used for growth. They would then have to be excreted, and since excretory processes are endergonic the elimination of these surplus nutrients would add to the total expenditure of energy by the larva. The Laws and Conservation of Energy and Mass require only that the growth rate and metabolic maintenance costs of a larva ingesting a fixed amount of food covary inversely, but it is not possible a priori to specify whether a change in growth rate is the cause or consequence of a change in metabolic rate.

Deciding whether reduced growth on a low-water diet is the cause or effect of increased expenditure of metabolic energy is not a trivial semantic issue. It is tantamount to identifying the adaptive mechanisms that permit a herbivorous insect to exploit dry foliage as food. If a low-water diet imposes high metabolic costs, which in turn cause efficiency of conversion of ingested food and growth rate to be low, then selection should favour energy efficiency in those pro- 
cesses that are responsible for the high metabolic costs. On the other hand, if the upper limit to the amount of new larval tissue that can be synthesized is set by the amount of water acquired from the diet, then selection should favour adaptations that extract and conserve the maximal amount of water from the food, even if those adaptations are energetically costly.

Another common, albeit less serious, misuse of terminology that has begun to appear in discussions of the consequences of dietary specialization is the designation of high metabolic maintenance costs, inferred from a low efficiency of conversion of ingested food, as high "processing costs" for a given food. "Processing cost" is an inappropriate term, because an insect's maintenance costs involve the expenditure of energy on many processes that are not directly related to the processing of food. If the term "processing cost" is destined to become a part of the jargon of nutritional ecology, it needs to be given a precise definition. We offer the following. A processing cost is a metabolic cost imposed by the operation of physiological and biochemical processes involved in extracting useful nutrients from ingested food, eliminating waste products generated during the processing of the food, and countering the potential harmful effects of toxins or other non-nutrient chemicals present in the food. Processing costs would, therefore, include the synthesis and secretion of digestive enzymes, the synthesis and secretion of the peritrophic membrane, the physical alteration and movement of material within the gut, the maintenance of appropriate ion and water fluxes between the haemocoel and the gut, the maintenance of gut $\mathrm{pH}$, the assimilation and absorption of nutrients, the resorption of water from the hindgut, the transformation of assimilated nutrients into a metabolite pool useful as a source of biosynthetic precursors or metabolic fuels, the synthesis and excretion of metabolic waste products, and the activation and operation of detoxification processes. This definition excludes costs associated with foraging or feeding, which we propose should be classified as acquisition costs. Acquisition costs may also depend to some extent upon the physical and chemical characteristics of the diet, but they will be far more dependent upon microclimatic conditions, habitat structure, the proximity of conspecifics, and other environmental factors. Other costs excluded from our definition of processing costs are those attendant to growth (the conversion of metabolites derived from the processing of assimilated nutrients from the food into larval biomass) and moulting. These are processes far removed from the processing of ingested food, although their magnitudes may not be totally independent of the composition of the diet. It cannot bc emphasized too strongly that the methods of quantitative nutrition rarely permit the identification of the physiological or biochemical processes that contribute to the metabolic maintenance costs of an animal, much less the quantification of their different contributions to the energy budget for animals on different diets.

In our research we have studied the growth, efficiency of food utilization, nitrogen budget, water budget, and energy metabolism of third-instar Man- duca sexta larvae on artificial diets containing different amounts of water. The results have allowed us to address the question of whether reduced growth on a low-water diet is due to increased processing costs or to limitations in the amount of water available for growth. Our conclusion is that although there is a directly measurable increase in the cost of processing the low-water diet, it is the absolute amount of water available that is responsible for reduced growth. While our work was in progress an excellent series of papers on the food intake, conversion efficiency, water economy, and feeding behavior of fifth-instar $M$. sexta larvae has appeared (Reynolds et al., 1985, 1986; Timmins et al., 1987).

\section{MATERIALS AND METHODS}

\section{Insects}

Tobacco hornworms, Manduca sexta, were reared from eggs (Carolina Biological Supply) on an artificial diet (Bio-Serv no. 9783) containing $82 \%$ water at $24^{\circ} \mathrm{C}$, under $16 \mathrm{~h}$ light $-8 \mathrm{~h}$ dark.

\section{Determination of growth, food consumption and faecal production}

Third-instar larvae, collected within one-half hour of moulting, were weighed and placed individually into $10-\mathrm{ml}$ shell vials containing preweighed portions of artificial diet (Bioserv no. 9783) initially containing either 82 or $65 \%$ water. The diet was held in place within the vial by a stainless steel pin inserted into the aluminum foil-wrapped rubber stopper. In order to maximize the accuracy of the nutritional indices calculated from these measurements (Schmidt and Reese, 1986), the quantity of food supplied was limited such that at least $75 \%$ was consumed by the larvae during the instar. The vials containing the larvae and their food were placed in an incubator $\left(24^{\circ} \mathrm{C}, 16 \mathrm{~h}\right.$ light $-8 \mathrm{~h}$ dark) until the larvae moulted to the fourth instar. Toward the end of the instar the larvae were observed every half hour, so that the time of the moult, and hence the duration of the instar, was known to within one-half hour. As soon as the larvae had moulted to the fourth instar, larvae, faeces and uneaten food were separated and dried to constant weight in an oven at $75^{\circ} \mathrm{C}$. The dry weights of the larvae at the beginning of the experiment were calculated from a live weight vs dry weight calibration curve obtained using newly moulted thirdinstar larvae comparable to the ones used in the experiment. Likewise, the dry weight of the food supplied initially was calculated from a wet weight vs dry weight calibration curve obtained by drying additional portions of the artificial diet.

\section{Nitrogen analysis}

The nitrogen content of artificial diet, larvae and faeces was determined by Kjeldahl analysis with a Tecator Kjeltec 1030 Auto Analyzer and Digestion System. Artificial diet was prepared for analysis by drying $\left(75^{\circ} \mathrm{C}, 72 \mathrm{~h}\right)$, passing through a Wiley Mill (40 mesh), and then grinding for $1 \mathrm{~h}$ in a mortar grinder. Larvae and faeces were dried $\left(75^{\circ} \mathrm{C}, 72 \mathrm{~h}\right)$ and ground for $1 \mathrm{~h}$ in a mortar grinder. Samples were digested at $420^{\circ} \mathrm{C}$ for $30 \mathrm{~min}$ in $3.0 \mathrm{ml}$ of concentrated sulphuric acid containing $1.5 \mathrm{~g}$ of potassium sulphate and 
$0.75 \mathrm{mg}$ of selenium (Kjeltab TC1 527). After cooling, the samples were diluted with $25 \mathrm{ml}$ of water, and $25 \mathrm{ml}$ of $35-40 \%$ sodium hydroxide was added to the digested sample in order to distil the ammonia into $25 \mathrm{ml}$ of $10 \%$ boric acid solution containing bromocresol green $(0.001 \%)$, methyl red $(0.0007 \%)$ and sodium hydroxide $(0.002 \%)$. Ammonia was titrated with $0.05 \mathrm{~N}$ hydrochloric acid.

\section{Nutritional indices}

Nutritional indices were calculated according to Waldbauer (1968). Relative rates of consumption and growth were based on the arithmetic mean of initial and final larval dry weights. All indices were calculated on a dry weight basis.

Abbreviations. RGR, relative growth rate; RCR, relative consumption rate; $A D$, approximate digestibility or assimilation efficiency; ECD, efficiency of conversion of digested food or net growth efficiency; ECI, efficiency of conversion of ingested food or gross growth efficiency; RNAR, relative nitrogen accumulation rate; RNCR, relative nitrogen consumption rate; $A D(N)$, approximate digestibility of nitrogen or nitrogen assimilation efficiency; $\operatorname{ECI}(\mathrm{N})=\mathrm{NUE}$, nitrogen utilization efficiency; $\mathrm{ECD}(\mathrm{N})$, efficiency of conversion of digested nitrogen.

$$
\begin{aligned}
& \mathrm{RGR}=\frac{\text { larval weight gained }}{\text { average larval weight during instar } \times \text { days }} \\
& \mathrm{RCR}=\frac{\text { weight of food ingested }}{\text { average larval weight during instar } \times \text { days }} \\
& \mathrm{AD}=\frac{\text { weight of food ingested }- \text { weight of frass }}{\text { weight of food ingested }} \\
& \mathrm{ECD}=\frac{\text { larval weight gained }}{\text { weight of food ingested }- \text { weight of frass }} \\
& \mathrm{ECI}=\frac{\text { larval weight gained }}{\text { weight of food ingested }}
\end{aligned}
$$$$
\text { RNAR }=\frac{\text { larval nitrogen gained }}{\text { average larval weight during instar } \times \text { days }}
$$$$
\mathrm{RNCR}=\frac{\text { nitrogen ingested }}{\text { average larval weight during instar } \times \text { days }}
$$

$$
\begin{aligned}
& \mathrm{AD}(\mathrm{N})=\frac{\text { nitrogen ingested }- \text { nitrogen excreted }}{\text { nitrogen ingested }} \\
& \mathrm{ECD}(\mathrm{N})=\frac{\text { larval nitrogen gained }}{\text { nitrogen ingested }- \text { nitrogen excreted }} \\
& \mathrm{ECI}(\mathrm{N})=\frac{\text { larval nitrogen gained }}{\text { nitrogen ingested }}
\end{aligned}
$$

Statistical comparisons of the above indices for larvae on each experimental diet were made using a Mann-Whitney U-test.

\section{Uric acid analysis}

Uric acid was determined by adapting the method of Bhattacharya and Waldbauer (1969) and Sigma
Procedure no. 292-u.v. Larvae and faeces were prepared for analysis by drying $\left(75^{\circ} \mathrm{C}, 72 \mathrm{~h}\right)$ and grinding in a mortar grinder $(1 \mathrm{~h})$. In addition, the dried ground larval biomass was defatted by extracting once with chloroform-methanol $(2: 1, \mathrm{v} / \mathrm{v})[1.5 \mathrm{ml} /$ $5 \mathrm{mg}$. Uric acid was extracted from a $5-\mathrm{mg}$ sample by two successive extractions in a $10-\mathrm{ml}$ tissue grinder, using first $3.0 \mathrm{ml}$ and then $2.0 \mathrm{ml}$ of $0.6 \%$ lithium carbonate, followed by centrifugation $(2200 \mathrm{rpm}$, $5 \mathrm{~min}$ ). The combined supernatant solutions were made up to a volume of $5.0 \mathrm{ml}$ with $0.1 \mathrm{M}$ glycine buffer $(\mathrm{pH} 9.4)$, centrifuged $\left(25^{\circ} \mathrm{C}, 9450 \mathrm{~g}, 5 \mathrm{~min}\right)$, and the pellet was discarded. To determine uric acid, $0.25 \mathrm{ml}$ of the extract and $2.75 \mathrm{ml}$ of $0.1 \mathrm{M}$ glycine buffer ( $\mathrm{pH}$ 9.4) were added to each of two replicate sample cuvettes and one blank cuvette. Sample cuvettes received $0.05 \mathrm{ml}$ of uricase solution (Sigma 292-8), while the blank cuvette received $0.05 \mathrm{ml}$ of deionized distilled water. The cuvettes were capped and inverted 5 times to mix. Following a 15-min incubation period, absorbance at $292 \mathrm{~nm}$ was recorded and checked at 15-min intervals until two successive readings changed less than $0.005 \mathrm{U}$. Uric acid content was calculated using the following formula.

mg uric acid per $g$ (dry wt) of sample

where

$$
=\frac{\mathrm{A}_{292} \times \mathrm{MW}_{\mathrm{ua}} \times \mathrm{V}_{\mathrm{inc}} \times \mathrm{V}_{\mathrm{ext}}}{\mathrm{e}_{\mathrm{ua}} \times \mathrm{V}_{\mathrm{alq}} \times \mathrm{W}_{\mathrm{sam}}}
$$

$A_{292}=$ absorbance at $292 \mathrm{~nm}$

$\mathrm{MW}_{\mathrm{ua}}=$ molecular weight of uric acid $=168.1 \mathrm{~g} / \mathrm{mol}$

$\mathrm{V}_{\text {inc }}=$ volume incubation mixture $=3.05 \mathrm{ml}$

$\mathrm{V}_{\mathrm{ext}}=$ volume of extract $=5.0 \mathrm{ml}$

$\mathrm{e}_{\mathrm{ua}}=$ extinction coefficient of uric acid $=$ $12,300 \mathrm{U}$

$\mathrm{V}_{\mathrm{alq}}=$ volume of aliquot $=0.25 \mathrm{ml}$

$\mathrm{W}_{\mathrm{sam}}=\mathrm{g}$ (dry wt) of sample

\section{Respiration rates}

Newly moulted third-instar larvae were fed in shell vials containing artificial diet of either 82 or $65 \%$-water content for $24 \mathrm{~h}$ prior to the measurement of respiration rates. Seven larvae from each diet were weighed and placed singly in 12 or $22 \mathrm{ml}$ respirometer flasks containing $0.5 \mathrm{ml}$ of distilled water in the sidearm and $0.4 \mathrm{ml}$ of $10 \%$ potassium hydroxide in the centre well, and the flasks were attached to the respirometer (Gilson Model No. GR 14). Larvae werc sedentary in the flasks. Following a 1-h equilibration period at $25^{\circ} \mathrm{C}$, oxygen consumption at $25^{\circ} \mathrm{C}$ was measured for $1 \mathrm{~h}$. Larvae, and faeces if present, were removed from the flask and weighed (see below for determination of transpirational water loss). Linear regressions of the natural logarithm of respiration rate on the natural logarithm of body dry weight were calculated. The water contents of 24-h old larvae were 86.3 and $81.5 \%$ on the $82 \%$ water diet and $65 \%$ water diets, respectively. Linear regressions for each diet were compared by an analysis of covariance, which identifies significant shifts in the $y$-intercept of the regression equations. 


\section{The water budget}

A water budget was constructed from experimentally determined values of water gained by ingestion and respiration, lost by defaecation and transpiration, and committed to growth by adjustment of tissue hydration level and production of new tissue. In the calculations described below, larval, faecal and food weights are dry weights. Units: mass, $\mathrm{mg}$; time, hours; respiration rate, $\mu \mathrm{l} / \mathrm{h}$.

The amount of water ingested by larvae during the third instar was calculated from the following formula.

Water ingested $=($ dry wt diet ingested $)$

$$
\times \frac{(\% \text { water in food })}{(100-\% \text { water in food })}
$$

Since the artificial diet supplied to the larvae at the beginning of the instar undergoes some dehydration during the course of the experiment, it is necessary to use an average value of the "\% water in food" rather than the initial value. In order to determine an average value, vials containing only artificial diet were placed in the same incubator with the vials containing the feeding larvae, and were sampled daily to determine the actual water content of the diet after 24,48 and $72 \mathrm{~h}$. This is an important correction to make, since food is the major source of water input for the larvae, and a small error in the water content of the food results in a large error in the calculated value of water ingested. The average value used was the arithmetic mean of the initial water content of the food, and the water content after 24 and $48 \mathrm{~h}$. The water content after $72 \mathrm{~h}$ was not included in the calculation of this mean, since virtually all feeding by the larvae occurs during the first $48 \mathrm{~h}$ of the instar.

Water produced by respiration of larvae was calculated from the following formula.

\section{Water from respiration}

$$
=\left(0.8 \times 10^{-3}\right) \text { (respiration rate) (instar duration) }
$$

The first term in the equation above, which has the units "mg water per $\mu 1$ oxygen", is calculated on the assumption that 1 mole of water is generated for each mole of oxygen consumed. The respiration rate was calculated from the regression equation of the natural log of respiration rate on the natural log of larval dry weight (Fig. 1). This calculation assumes that the observed respiration rate, measured over a 1-h period, is an accurate measure of the average respiration rate over the entire instar. This is doubtless an invalid assumption (Wrightman, 1981; McEvoy, 1985), but since water gained from respiration contributes so little to the water budget, it introduces little error into the calculations.

The amount of water lost in faeces by larvae during the third instar was calculated from the following formula.

Water lost in faeces

$$
\begin{gathered}
=(\text { dry weight of faeces excreted }) \\
\times \frac{(\% \text { water in faeces })}{(100-\% \text { water in faeces })}
\end{gathered}
$$

This is the least accurate term in the water budget,

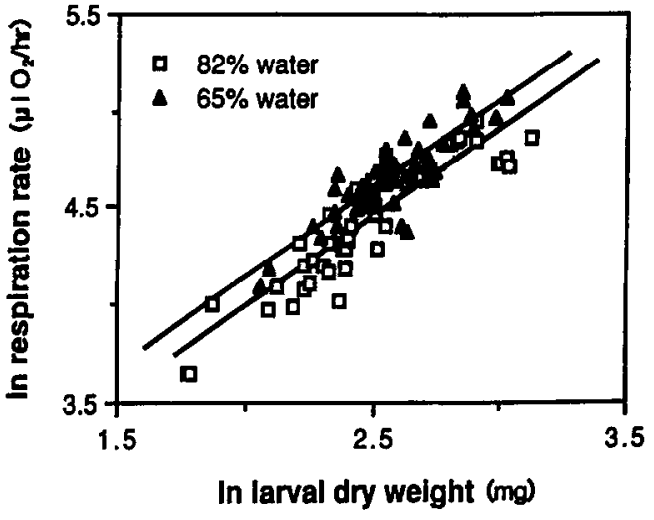

Fig. 1. Respiration rate as a function of larval dry weight for third instar Manduca sexta larvae following ingestion of artificial diets of $82 \%(\square)$ or $65 \%$ ( $\triangle$ ) water. Regression equations for natural $\log$ transformed data are $y=0.915 x+2.156$ and $y=0.915 x+2.304$ for diets of 82 and $65 \%$ water, respectively. The analysis of covariance is significant at $P<0.0001$.

due to the difficulty of measuring the water content of the faecal pellets at the instant they are produced. An underestimate results, because newly produced faecal pellets lose water very rapidly. In order to minimize the error in the measurement of faecal water content, all weight determinations were made on pellets within $10 \mathrm{~min}$ of their production by mid-instar larvae. Measurements on individual freshly produced pellets were not feasible owing to their small size and weight.

Transpirational water loss was determined by measuring larval weight loss, corrected for the wet weight of any faeces produced, during the $2 \mathrm{~h}$ in which respiration was measured (see above). It was assumed that this rate is representative of the average rate over the entire instar.

In calculating the amount of water allocated to growth it is necessary to recognize two components of growth: (1) the adjustment of the level of tissue hydration from that at the beginning of the instar to that at the end, and (2) the synthesis of new tissue. For the purposes of computation it is convenient to assume that these two components occur separately, that is, that first the newly moulted larva gains (or loses) water to reach the hydration level characterization of the end of the instar, and then that all new tissue that is synthesized has the hydration level characteristic of the end of the instar.

The amount of water required to adjust the initial (i) hydration level to the final (f) hydration level was calculated from the following formula.

Water required to adjust the hydration level of tissue

$$
\begin{aligned}
= & \text { (initial larval dry wt) } \\
& \times\left[\left(\frac{\% \text { water in larva }}{100-\% \text { water in larva }}\right),\right. \\
& \left.-\left(\frac{\% \text { water in larva }}{100-\% \text { water in larva }}\right)_{i}\right]
\end{aligned}
$$

This quantity is a positive number for larvae on the 
high water diet, since their hydration level increases during the third instar from 83.1 to $88.1 \%$, and a negative number for larvae on the low-water diet since their hydration level decreases from 83.1 to $81.3 \%$.

The amount of water used in producing new tissue was calculated from the following formula.

Water used in new tissue

$$
\begin{gathered}
=(\text { larval dry weight gain }) \\
\times \frac{(\% \text { water in larva })}{(100-\% \text { water in larva })}
\end{gathered}
$$

The accuracy of this calculation is highly dependent upon the accuracy with which the water content of the larvae is determined.

\section{Effect of switching diets on water content of larvae and frass}

The water content of newly moulted third-instar larvae which had been reared on the diet containing $82 \%$ water was determined by weighing the live larvae, killing them by freezing, drying them in an oven at $75^{\circ} \mathrm{C}$, and reweighing them. Ninety-three newly moulted third-instar larvae were placed individually in shell vials containing artificial diet with an initial water content of either 82 or $65 \%$. After 24 and $48 \mathrm{~h}, 8-16$ larvae from each diet were removed from their vials, weighed, dried and reweighed to determine their water contents. Also, after $24 \mathrm{~h}$, 15-23 larvae from each diet were switched onto the other diet. $24 \mathrm{~h}$ after this diet switch $(48 \mathrm{~h}$ following the moult), half of these larvae were removed, weighed, dried and reweighed. $48 \mathrm{~h}$ after the diet switch ( $72 \mathrm{~h}$ following the moult), the remaining larvae were removed, weighed, dried and reweighed. Thus, larval water content was determined for larvae at the onset of the third instar, for larvae that had fed continuously for 24 or $48 \mathrm{~h}$ on either a high- or a low-water diet, and for larvae that had fed for $24 \mathrm{~h}$ on either a high- or low-water diet, followed by an additional 24 or $48 \mathrm{~h}$ on a diet with a water content either higher or lower than the one they had fed upon during their first $24 \mathrm{~h}$ after moulting.

To determine the effect of switching from a highto a low-water diet on faecal water content, newly moulted larvae which had been reared to the third instar on the $82 \%$ water diet were placed individually in shell vials containing the $82 \%$ water diet. After $24 \mathrm{~h}$ all faeces were removed so that determinations of water content could be made on fresh faecal pellets produced subsequently. Faecal pellets were collected, weighed, dried and reweighed during three successive 10 -min intervals. The $82 \%$ water diet was then removed and replaced with the $65 \%$ water diet, and the larvae were allowed to feed undisturbed for $1.5 \mathrm{~h}$. Thereafter, newly produced faecal pellets were collected, weighed, dried and reweighed during $30-\mathrm{min}$ intervals, divided into three successive 10 -min intervals, beginning $2.5,4.0,5.0$ and $6.0 \mathrm{~h}$ after the switch from the $82 \%$ to the $65 \%$ water diet.

\section{RESULTS}

\section{Growth and efficiency of food utilization}

Relative growth rates of third-instar $M$. sexta larvae are significantly lower on an artificial diet containing $65 \%$ water than one containing $82 \%$ water (Table 1 ). The reduced growth rate on the low-water diet is a consequence of a lower efficiency of conversion of digested food into larval biomass, $52.7 \%$ for larvae on the $82 \%$ water diet and only $40.9 \%$ for larvae on the $65 \%$ water diet. This result is in complete agreement with earlier studies of the growth of fourth- and fifth-instar larvae of $\mathrm{Hya}$ lophora cecropia larvae on black cherry foliage with different moisture contents (Scriber, 1977) and of 10-20-day old Agrotis ipsilon larvae (Reese and Beck, 1978) and fifth-instar M. sexta larvae (Timmins et al., 1987) on artificial diets with different water contents.

\section{The nitrogen budget}

Relative nitrogen accumulation rates are significantly lower for third-instar $M$. sexta larvae on the artificial diet containing $65 \%$ water than on the one containing $82 \%$ water, and the lower rate of nitrogen accumulation is due to reduced efficiency of conversion of digested nitrogen into larval biomass (Table 2). This result is in accord with Scriber's (1977) conclusion that on low-moisture diets larval growth is suppressed by reduced efficiency in using assimilated nitrogen for growth. The values in Table 2 have been corrected for the presence of uric acid in the faeces and the larvae, but not for the possible presence of allantoin and allantoic acid, two other nitrogenous excretory products commonly produced by caterpillars (Bursell, 1975). The difference between the values of efficiency of conversion of digested nitrogen for the larvae on the two diets might be even greater than represented in Table 2 if the nutritional indices were corrected for the presence of these two substances.

Larvae on the low-water diet ingest $24.7 \%$ more nitrogen $(2.83 \mathrm{mg}$ vs $2.27 \mathrm{mg}$ ) than larvae on the

Table 1. Nutritional indices (mean and SE) of third-instar Manduca sexta larvae reared on artificial diets with initial water contents of 82 or $65 \%$

\begin{tabular}{lccc}
\hline & \multicolumn{2}{c}{ Initial water content of diet } & \\
\cline { 2 - 3 } Nutritional index & $82 \%$ & $65 \%$ & $P$ value \\
\hline RGR $(\mathrm{mg} /$ day $/ \mathrm{mg})$ & $0.44 \pm 0.007$ & $0.37 \pm 0.007$ & 0.0001 \\
RCR (mg/day/mg) & $1.89 \pm 0.027$ & $1.94 \pm 0.034$ & 0.1049 \\
AD $(\%)$ & $44.9 \pm 0.41$ & $47.2 \pm 0.56$ & 0.0064 \\
ECD $(\%)$ & $52.7 \pm 0.81$ & $40.9 \pm 0.68$ & 0.0001 \\
ECI $(\%)$ & $23.6 \pm 0.34$ & $19.2 \pm 0.20$ & 0.0001 \\
\hline
\end{tabular}

Significance levels are given for Mann-Whitney U-tests. The number of replicates was 33 for the $82 \%$ water diet and 36 for the $65 \%$ water diet.

See Materials and Methods for abbreviations of nutritional indices. 
Table 2. Utilization of dietary nitrogen (mean and SE) of third instar Manduca sexta larvae reared on artificial diets with initial water contents of 82 or $65 \%$

\begin{tabular}{lccc}
\hline & \multicolumn{2}{c}{ Initial water content of diet } & \\
\cline { 2 - 3 } Nutritional index & $82 \%$ & $65 \%$ & \multirow{2}{*}{$P$ value } \\
\hline RNAR (mg/day/mg) & $0.044 \pm 0.0007$ & $0.036 \pm 0.0007$ & 0.0001 \\
RNCR (mg/day/mg) & $0.073 \pm 0.0011$ & $0.075 \pm 0.0013$ & 0.1049 \\
AD(N) (\%) & $82.8 \pm 0.13$ & $79.7 \pm 0.21$ & 0.0001 \\
ECD(N) (\%) & $72.3 \pm 1.03$ & $59.6 \pm 0.68$ & 0.0001 \\
ECI(N) (\%) & $59.8 \pm 0.86$ & $47.4 \pm 0.50$ & 0.0001 \\
\hline
\end{tabular}

Values are corrected for uric acid content of larvae and faeces. Significance levels are given for Mann-Whitney U-tests. The number of replicates was 33 for the $82 \%$ water diet and 36 for the $65 \%$ water diet.

See Materials and Methods for abbreviations of nutritional indices.

Table 3. Ingestion, assimilation, and utilization of nitrogen (mean and SE) by third instar Mandica sexta larvae reared on artificial diets with initial water contents of 82 or $65 \%$

\begin{tabular}{lcc}
\hline & \multicolumn{2}{c}{ Initial water content of diet } \\
Category of nitrogen & $82 \%$ & $65 \%$ \\
\hline $\begin{array}{l}\text { Total nitrogen ingested }(\mathrm{mg}) \\
\begin{array}{l}\text { Non-uric acid nitrogen } \\
\text { assimilated }(\mathrm{mg})\end{array}\end{array}$ & $2.27 \pm 0.081$ & $2.83 \pm 0.087$ \\
$\begin{array}{l}\text { Non-uric acid nitrogen } \\
\text { utilized in growth }(\mathrm{mg})\end{array}$ & $1.88 \pm 0.067$ & $2.25 \pm 0.069$ \\
\hline
\end{tabular}

Values for nitrogen assimilated and utilized for growth have been corrected for the presence of uric acid in faeces and larvae. The number of replicates was 33 for the $82 \%$ water diet and 36 for the $65 \%$ water diet.

high-water diet (Table 3). The amount of nitrogen assimilated during the third instar $[\mathrm{mg} N$ ingested $\times$ approximate digestibility ( $\mathrm{N}$-corrected for uric acid)] is $19.7 \%$ higher $(2.25 \mathrm{mg}$ vs $1.88 \mathrm{mg})$ in larvae on the low-water diet. Despite the larger amount of assimilated nitrogen available to them, the larvae on the low-water diet do not produce significantly more new tissue nitrogen $(1.37 \mathrm{mg})$ than the larvae on the high-water diet $(1.34 \mathrm{mg})$.

The nitrogen budgets do not quite balance (Table 4). Faecal nitrogen and nitrogen used for growth account for only $85 \%$ of the nitrogen ingested by the larvae. The discrepancy seems most likely to be due to the loss of ammonia from the frass during drying (Powning, 1953; Pramila and Krishnamoorthy, 1977).

Uric acid production is significantly greater in larvae from the diet containing $65 \%$ water than in larvae from the diet containing $82 \%$ water (Table 5). Larvae from the low-water diet contain twice as much uric acid, and their faeces 2.5-times as much, as larvae from the high-water diet. Analysis of uric acid levels in different tissues suggests that the additional uric acid in the third-instar larvae from the low-water diet is located primarily in the cuticle (Van't Hof, unpublished results)

\section{Respiration rates}

Larvae maintained for the first $24 \mathrm{~h}$ of the third instar on a diet containing $65 \%$ water have a respiration rate, calculated on a larval dry weight basis, that is $16.0 \%$ higher than larvae maintained on a diet containing $82 \%$ water (Fig. 1). This increment in the respiration rate is observed in individuals of varying size, representing the entire size range of mid-thirdinstar larvae. The larvae used in these experiments were in the active feeding stage, but were not allowed to feed for $1 \mathrm{~h}$ prior to the initiation of the measurement of respiration or during the hour when the measurement was made. Thus, the observed metabolic rates do not include feeding costs or other food acquisition costs. The metabolic rates of actively feeding caterpillars have been reported to be 1.6-2.0 as high as those of non-feeding larvae (Aidley, 1976; McEvoy, 1984). The metabolic rates we have measured are best interpreted as summations of maintenance metabolism (basal metabolism), the

Table 4. Nitrogen budgets of third-instar Manduca sexta larvae reared on artificial diets with initial water contents of 82 or $65 \%$

\begin{tabular}{lll}
\hline $\begin{array}{l}\text { Source of } \\
\text { nitrogen } \\
\text { gain or loss }\end{array}$ & \multicolumn{2}{c}{ Nitrogen gained or lost (mg) } \\
\cline { 2 - 3 } & High-water diet & Low-water diet \\
\hline $\begin{array}{l}\text { GAIN } \\
\text { Food }\end{array}$ & $2.27 \pm 0.081$ & $2.83 \pm 0.087$ \\
LOSS & & \\
Faeces & $0.48 \pm 0.018$ & $0.84 \pm 0.029$ \\
Growth & $\underline{1.45 \pm 0.058}$ & $\frac{1.55 \pm 0.049}{2.39 \pm 0.076}$ \\
TOTAL & $1.93 \pm 0.074$ &
\end{tabular}

Values are means and SE, and the number of replicates was 33 for the $82 \%$ water diet and 36 for the $65 \%$ water diet.

Table 5. Uric acid content (mean and range) of third-instar Manduca sexta larvae and their faeces when larvae are reared on artificial diets with initial water contents of 82 or $65 \%$

\begin{tabular}{lcc}
\hline \multirow{2}{*}{$\begin{array}{l}\text { Material } \\
\text { analyzed }\end{array}$} & \multicolumn{2}{c}{ Uric acid content (\%) } \\
\cline { 2 - 3 } Faeces & High-water diet & Low-water diet \\
Larvae & $0.83(0.76-0.87)$ & $2.08(2.08-2.09)$ \\
\hline
\end{tabular}

Individuals from each treatment were pooled at the end of the instar ( $n=33$ for the $82 \%$ water diet and $n=36$ for the $65 \%$ water diet), and the mean is based on two determinations. 
Table 6. Water budgets of third-instar Manduca sexta larvae reared on artificial diets with initial water contents of 82 or $65 \%$, and average water contents during the time when larvae were feeding of 80.6 or $61.6 \%$

\begin{tabular}{lcc}
\hline \multirow{2}{*}{$\begin{array}{l}\text { Source of water } \\
\text { gain or loss }\end{array}$} & \multicolumn{2}{c}{ Water gained or lost (mg) } \\
\cline { 2 - 3 } $\begin{array}{l}\text { GAIN } \\
\text { Food }\end{array}$ & High-water diet & Low-water diet \\
$\begin{array}{l}\text { Respiration } \\
\text { Adjustment of initial } \\
\text { level of larval hydration }\end{array}$ & $243.9 \pm 8.69$ & $118.4 \pm 3.66$ \\
TOTAL & $4.6 \pm 0.17$ & $6.0 \pm 0.19$ \\
LOSS & - & $1.7 \pm 0.34$ \\
Faeces & $248.5 \pm 8.86$ & $126.1 \pm 3.73$ \\
Transpiration & & \\
Adjustment of initial & $110.7 \pm 4.04$ & $36.3 \pm 1.23$ \\
$\quad$ level of larval hydration & $21.6 \pm 0.88$ & $17.8 \pm 0.61$ \\
Growth & $9.3 \pm 0.70$ & - \\
TOTAL & $\underline{104.1 \pm 4.53}$ & $62.3 \pm 2.69$ \\
\hline Consul Materials and & $245.6 \pm 9.58$ & $116.4 \pm 4.27$ \\
\hline
\end{tabular}

Consult Materials and Methods for the procedures used to calculate the water gained or lost by each pathway. Values are means and SE, and the number of replicates was 33 for the $82 \%$ water diet and 36 for the $65 \%$ water diet.

metabolism involved in growth processes, and the metabolic costs associated with the processing of ingested and assimilated food.

\section{The water budget}

Food is the major source of water for the larvae, with metabolic water making only a very minor contribution to the total input (Table 6). Larvae on the high-water diet gain more than twice as much water from their food than larvae on the low-water diet. Faecal excretion is the main avenue by which water is lost, but a significant amount is also lost by transpiration. Larvae on the high-water diet lose more than 3 times as much water in the faeces than larvae on the low-water diet. Changes in the level of tissue hydration between the beginning and end of the instar also affect the amount of water available for the synthesis and hydration of new tissue. Larvae on the low-water diet decrease the water content of their tissues from 83.1 to $81.3 \%$, and in so doing make a small amount of additional water available for the synthesis of new tissue. By contrast, larvae on the high-water diet must commit a small amount of the water they have gained from their food and from metabolism to increasing the hydration level of their tissues from 83.1 to $88.1 \%$, thus removing it from the pool available for the hydration of new tissue. After all avenues of water gain have been taken into account, the larvae on the low-water diet gain only $50.7 \%$ as much water (126.1 $\mathrm{mg}$ vs $248.5 \mathrm{mg}$ ) as the larvae on the high-water diet.

Larvae from the low-water diet retain and use water much more efficiently than larvae from the high-water diet (Tables 6 and 7). They use $49.4 \%$ of the water available to them for the hydration of new tissue $(62.3 \mathrm{mg}$ out of $126.1 \mathrm{mg}$ ), while the larvae on the high-water diet use only $41.9 \%$ (104.1 mg out of $248.5 \mathrm{mg}$ ). The greater efficiency of the larvae from the low-water diet in retaining the water they have gained is due to their ability to produce much drier faeces than larvae from the high-water diet $(48.1 \%$ water vs $77.3 \%$ water) [Table 7]. When larvae are switched from a diet containing $82 \%$ water to one containing $65 \%$ water, a decline in the water content of the faeces is evident within $1.5 \mathrm{~h}$ following the switch and continues steadily thereafter (Fig. 2). On both diets the faeces are drier than the food, and the difference between the water content of the diet and

Table 7. Measures of efficiency with which third-instar Manduca sexta larvae reared on artificial diets with initial water contents of 82 and $65 \%$ retain and use water for growth

\begin{tabular}{|c|c|c|}
\hline \multirow[b]{2}{*}{ Measure } & \multicolumn{2}{|c|}{ Initial water content of diet } \\
\hline & $82 \%$ & $65 \%$ \\
\hline $\begin{array}{l}\text { Amount of available } \\
\text { water that is } \\
\text { used for growth }(\%)\end{array}$ & 41.9 & 49.4 \\
\hline Water content of faeces $(\%)$ & $\begin{array}{c}77.3=0.57 \\
n=10\end{array}$ & $\begin{array}{l}48.1 \pm 1.39 \\
n=9\end{array}$ \\
\hline $\begin{array}{l}\text { Difference between water } \\
\text { content }(\%) \text { of food and faeces }\end{array}$ & 4.7 & 16.9 \\
\hline Water content of larvae $(\%)$ & $\begin{array}{c}88.1 \pm 0.17 \\
n=33\end{array}$ & $\begin{array}{c}81.3 \pm 0.35 \\
n=36\end{array}$ \\
\hline $\begin{array}{l}\text { Dry weight (mg) of new larval } \\
\text { tissue that can be synthesized } \\
\text { when } 1 \mathrm{mg} \text { of water is available } \\
\text { to hydrate the new tissue }\end{array}$ & 0.135 & 0.230 \\
\hline
\end{tabular}

Values for water contents of faeces and larvae are means and SE. 


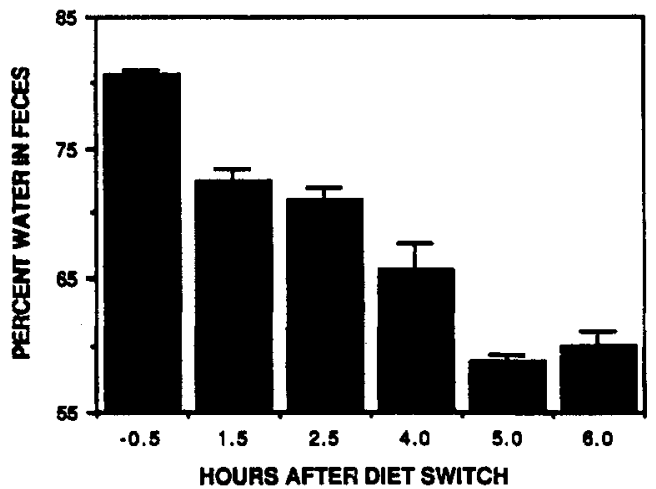

Fig. 2. Change in water content of faeces of third-instar Manduca sexta larvae following a switch from a high-water $(82 \%)$ diet to a low-water $(65 \%)$ diet. Larvae were reared through the second instar on the high-water diet and were switched from the high-water to the low-water diet $24 \mathrm{~h}$ after their moult to the third instar.

the faeces is greater in larvae from the low-water diet than from the high-water diet $(16.9 \%$ vs $4.7 \%)$ [Table 7]. These results indicate a significant capacity on the part of $M$. sexta larvae to resorb water from the contents of the hindgut when their diet is low in water.

Larvae on the low-water diet synthesize $70 \%$ more new tissue using a given amount of water than their counterparts on the high-water diet $(0.230$ vs $0.135 \mathrm{mg}$ dry weight per $\mathrm{mg}$ water), because larvae from the low-water diet are less highly hydrated than larvae from the high-water diet $(81.3$ vs $88.1 \%)$ [Table 7].

The values of water content of the larvae reported in Table 7 are for newly moulted fourth-instar larvae that had fed on the diet indicated for the entire third instar. It is also possible to document changes in water content of larvae which are switched between high- and low-water diets during the third instar (Fig. 3). Thus, larvae containing $83.1 \%$ water at the onset of the third instar have a water content of $81.5 \% 24 \mathrm{~h}$ after being switched onto a $65 \%$-water diet (Group A, Fig. 3), but then increase their water content to $86.5 \% 24 \mathrm{~h}$ after being switched back to an $82 \%$-water diet (Group A', Fig. 3). By contrast, in

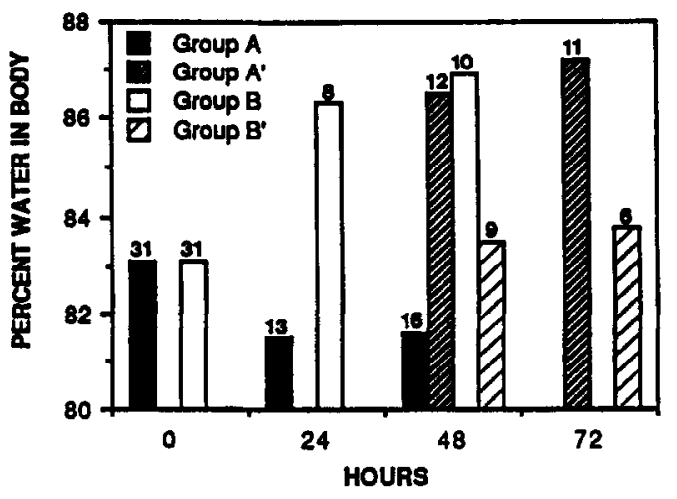

Fig. 3. Changes in water content of third-instar Manduca sexta larvae switched between diets of different water contents. Larvae were reared through the second instar on the $82 \%$ water diet. Group A was transferred to the $65 \%$ water diet immediately following the moult to the third instar, while Group B remained on the $82 \%$ water diet following the moult to the third instar. Group A' was a sub-group of Group A, switched from the $65 \%$ water diet to the $82 \%$ water diet $24 \mathrm{~h}$ following the moult to the third instar. Group B' was a sub-group of Group B, switched from the $82 \%$ water diet to the $65 \%$ water diet $24 \mathrm{~h}$ following the moult to the third instar. Numbers above columns represent sample sizes. Standard error bars have been omitted as they are too small to be accurately represented in the figure.

larvae kept on the $82 \%$ water diet for $24 \mathrm{~h}$ the water content increases from its initial value of 83.1 to $86.3 \%$ (Group B, Fig. 3), and then decreases to $83.5 \%$ when switched to the $65 \%$ water diet (Group B', Fig. 3). Although we did not make measurements at sufficiently short intervals to obtain an accurate determination of the rate at which the hydration level changes, it must be fairly rapid since it is virtually complete within $24 \mathrm{~h}$. The water content of the larvae $48 \mathrm{~h}$ after being placed on either diet differed very little from the value after $24 \mathrm{~h}$. It is interesting to note that larvae switched from the $82 \%$-water diet to the $65 \%$-water diet during the third instar (Group B', Fig. 3) do not attain as low a water content even after $48 \mathrm{~h}$ as the larvae placed on the $65 \%$-water diet from the beginning of the third instar (Group A, Fig. 3) [83.8 vs $81.6 \%$ ].

Table 8. Calculation of a hypothetical value of efficiency of conversion of digested food assuming an increase in respiration rate of $16.0 \%$

\begin{tabular}{|c|c|c|c|}
\hline Quantity & Computation & Case I & Case 2 \\
\hline 1. Food consumed (mg) & (wt larval) $(\mathrm{RCR})(\Delta t)$ & 58.9 & 70.5 \\
\hline 2. Food assimilated (mg) & (1) (AD) & 26.5 & 33.3 \\
\hline 3. Food used for growth (mg) & (2) (ECD) & 13.9 & 17.5 \\
\hline 4. Food used for energy (mg) & (2)-(3) & 12.6 & 15.8 \\
\hline $\begin{array}{l}\text { 5. Food used for energy } \\
\text { with } 16.0 \% \text { increase } \\
\text { in metabolism (mg) }\end{array}$ & $(1.160)(4)$ & 14.6 & 18.3 \\
\hline $\begin{array}{l}\text { 6. Food left over for growth } \\
\text { with } 16.0 \% \text { increase in } \\
\text { metabolism (mg) }\end{array}$ & $(2)-(5)$ & 11.9 & 15.0 \\
\hline $\begin{array}{l}\text { 7. Predicted new ECD } \\
\text { with } 16.0 \% \text { increase } \\
\text { in metabolism }\end{array}$ & $(6) /(2)$ & $44.8 \%$ & $45.0 \%$ \\
\hline
\end{tabular}

Calculations are for a larva weighing $10.50 \mathrm{mg}$ (dry wt) with an ECD of $52.7 \%$ before the assumed increase in respiration rate. Case $\mathrm{I}: \mathrm{RCR}=1.89 \mathrm{mg} / \mathrm{d} / \mathrm{mg}, \mathrm{AD}=44.9 \%, \Delta t=2.97 d$ (values for a larva on the $82 \%$ water diet). Case $2: \mathrm{RCR}=1.94 \mathrm{mg} / \mathrm{d} / \mathrm{mg}, \mathrm{AD}=47.2 \%, \Delta t=3.46 d$ (values for a larva on the $65 \%$ water diet).

See Materials and Methods for abbreviations of nutritional indices. 
Table 9. Calculations of hypothetical values of efficiency of conversion of digested food, assuming different values for the percentage of total water input that is retained for growth and the mg (dry wt) of new tissue that can be synthesized per $\mathrm{mg}$ of water available

\begin{tabular}{|c|c|c|c|c|}
\hline Quantity & Case 1 & Case 2 & Case 3 & Case 4 \\
\hline Total water available $(\mathrm{mg})$ & 115.1 & 115.1 & 126.1 & 126.1 \\
\hline Food assimilated $(\mathrm{mg})$ & 34.8 & 34.8 & 34.8 & 34.8 \\
\hline \multicolumn{5}{|l|}{ Water retained } \\
\hline Percentage & 41.9 & 49.4 & 41.9 & 49.4 \\
\hline Weight (mg) & 48.2 & 56.9 & 52.8 & 62.3 \\
\hline \multicolumn{5}{|l|}{ New tissue synthesized } \\
\hline $\mathrm{Mg}$ dry wt/mg water & 0.135 & 0.135 & 0.230 & 0.230 \\
\hline Weight (mg) & 6.5 & 7.7 & 12.1 & 14.3 \\
\hline $\begin{array}{l}\text { Calculated efficiency of conversion } \\
\text { of digested food } \%\end{array}$ & 18.7 & 22.1 & 34.9 & 41.2 \\
\hline
\end{tabular}

Calculations are for a larva weighing $10.98 \mathrm{mg}$ (dry wt) with $\mathrm{RCR}=1.94 \mathrm{mg} / \mathrm{d} / \mathrm{mg}, \mathrm{AD}=47.2 \%$, and $\Delta t=3.46 d$, on a diet with average water content of $61.6 \%$. The total input of water would be at least $124.4 \mathrm{mg}$ (118.4 $\mathrm{mg}$ from the food, $6.0 \mathrm{mg}$ from oxidative metabolism). Cases 1 and 2 assume that $9.3 \mathrm{mg}$ of water have to be used to adjust the tissue hydration level of the larva, whereas Cases 3 and 4 assume that the adjustment of tissue hydration level makes an additional $1.7 \mathrm{mg}$ of water available. Refer to Discussion for an explanation of the significance of the efficiency parameters chosen for the calculations in the four cases illustrated.

See Materials and Methods for abbreviations of nutritional indices.

\section{DISCUSSION}

This work has confirmed a number of conclusions derived from earlier studies. Reduced larval growth on a low-water diet is due to a lower efficiency of conversion of digested food to larval tissue (Scriber, 1977; Reese and Beck, 1978; Timmins et al., 1987), and especially to a reduced efficiency of conversion of digested nitrogen (Scriber, 1977). Food is the major source of water input, and faecal excretion is the major avenue of water loss (Reynolds et al., 1987). However, several important new insights can be derived from this work, because it combines in a single study accurate measurements of an overall mass balance, a nitrogen budget, and a water budget with determinations of uric acid production and aerobic energy metabolism.

For example, this study demonstrates that there is a measurably higher metabolic cost of processing an artificial diet containing $65 \%$ water than one containing $82 \%$ water. Larvae on the low-water diet respire at a rate $16.0 \%$ higher than larvae on the high-water diet. Since the measurements were made on inactive non-feeding larvae that had not fed for at least an hour, on the second day of the instar at least $24 \mathrm{~h}$ before the onset of any premoulting activities, the recorded respiratory activity cannot be attributed to processes associated with moulting or the acquisition of food. It must be a composite measure of basal metabolism, the energy expended for the processing of ingested and assimilated food, and the energy expended for growth. Therefore, the increase of $16.0 \%$ in respiratory rate observed in the larvae from the low-water diet represents the maximal increase in metabolic costs that can be attributed to the postingestive processing of the low-water diet during the second hour after the ingestion of food.

We can identify two processes that seem likely to contribute to the higher cost of processing the lowwater diet. These are the withdrawal of water from the contents of the rectum and the synthesis of uric acid. Both occur to a greater extent in the larvae on the low-water diet than in the larvae on the highwater diet.

The caterpillars on the low-water diet produce much drier faeces and retain a much higher proportion of the water they acquire than the larvae on the high-water diet. The resorption of water from the rectum is an endergonic process, since it is dependent upon the activation of ion pumps in the rectal epithelium (Phillips et al., 1986). The greater efficiency of the larvae on the low-water diet at resorbing water from the rectum is clearly of great benefit since it makes more water available for growth, but this adaptive mechanism carries with it a metabolic cost.

The synthesis of uric acid is also an endergonic process. The synthesis of 1 mole of uric acid requires the expenditure of $5 \mathrm{~mol}$ of ATP (Lehninger, 1975). Since the larvae on the low-water diet produce 2-2.5-times as much uric acid as the larvae on the high-water diet, some portion of the increase in the metabolic cost of processing the low-water diet must be due to the increased rate of synthesis and excretion of this substance.

In Table 8 we have calculated the hypothetical reduction in efficiency of conversion of digested food from the value of $52.7 \%$ observed for the larvae on the high-water diet if there were to be an increase in the metabolic rate of $16.0 \%$ over the entire duration of the instar. The key assumption in this calculation of a hypothetical efficiency of conversion is that an increase of $16.0 \%$ in the respiration rate will result in the diversion of an additional $16.0 \%$ of the assimilated food into energy metabolism and away from growth. We have made the calculations for a thirdinstar larva of average dry weight $(10.50 \mathrm{mg})$ and have used values of relative consumption rate, approximate digestibility, and instar duration typical for both larvac on the $82 \%$-water diet (Case 1) and larvae on the $65 \%$-water diet (Case 2). The predicted values for efficiency of conversion of digested food are 44.8 and $45.0 \%$ for Cases 1 and 2 , respectively. Thus, an increase in metabolic rate of $16.0 \%$ explains only $65-67 \%$ of the observed decrease in efficiency of conversion from $52.7 \%$ (the value for larvae on the high-water diet) to $40.9 \%$ (the value for larvae on the low-water diet). From this analysis we conclude that food processing costs alone cannot fully account for the reduced growth of larvae on the low-water diet. 
These calculations fail to predict the efficiency of conversion of digested food observed for larvae on the low-water diet because the $16.0 \%$ increase in respiration rate recorded during a $1-\mathrm{h}$ period on the second day of the instar underestimated the actual percentage increase in the amount of assimilated food that was committed to energy metabolism over the entire instar. An increase of $24.3 \%$ in total energy expenditure, or more precisely, in the amount of assimilated food diverted to energy metabolism and away from growth, is required to explain a decrease in efficiency of conversion of digested food from 52.7 to $40.9 \%$. We can envision two possible causes for the failure of the increment in respiratory rate during the measurement interval to predict the increment over the entire instar. It is possible that activities that occur at other times during the instar, such as food acquisition or moulting, might have different metabolic costs for larvae on the low-water diet which result in metabolic rates more than $16 \%$ higher than those of larvae on the high-water diet. Alternatively, it is possible that the larvae on the low-water diet simply spend more time than larvae on the high-water diet in activities with high metabolic costs compared to activities with low metabolic costs (e.g. food acquisition and processing vis à vis inactive nonfeeding premoult activities). Work is in progress to characterize the difference in energy expenditure over the entire instar of larvae on the two diets (Van't Hof, unpublished results).

This study provides strong support for the idea that on diets low in water the upper limit to the amount of new tissue that can be synthesized is set by the amount of water the larvae can extract from their food. First, the elevated production of uric acid by the larvae on the low-water diet is in accord with the idea that water is the growth-limiting nutrient in this diet. Even though larvae on the low-water diet both ingest and assimilate more nitrogen than larvae on the high-water diet, the increase in the pool of assimilated nitrogen does not enable these larvae to produce more new tissue during the third instar. The extra nitrogen assimilated is, therefore, a liability rather than an asset since it must be excreted. Clearly, on this diet growth is limited by something other than nitrogen, and since the two diets differ only in water content, water is the logical candidate for the growthlimiting nutrient on the low-water diet. It is interesting to note in this regard that nitrogen has been shown not to be a growth-limiting nutrient for larval Lepidoptera and Hymenoptera fed leaves with greater than 3\% (dry weight) nitrogen (Schroeder, 1976, 1986; Schroeder and Malmer, 1980). Schroeder (1986) has also noted that water may be the primary limiting nutrient for tree-feeding folivores, and that when water is limiting, surplus protein "contrary to providing useful nutrients, actually places a metabolic load on the larvae".

As a further confirmation of the quantitative importance of water as a nutrient, we have identified two adaptive mechanisms that contribute to the ability of larvae to grow on a low-water diet. These adaptations are (1) the ability to resorb water from the contents of the rectum to produce faeces much drier than the food, and (2) the ability to tolerate lower levels of tissue hydration and to reduce hy- dration levels in response to reduced water intake. The importance of these two adaptations to growth on low-water diets is illustrated in Table 9, in which hypothetical values of efficiency of conversion have been calculated for a larva possessing neither, one or both of these adaptations. The calculations are for a larva that assimilates a total of $34.8 \mathrm{mg}$ of its food and has a total input of water of at least $124.4 \mathrm{mg}$, values appropriate for a larva of average size (dry wt $10.98 \mathrm{mg}$ ) on a low-water diet. Cases 1 and 2 assume that $9.3 \mathrm{mg}$ of water have to be used to adjust the tissue hydration level of the larva, whereas Cases 3 and 4 assume that the adjustment of tissue hydration level makes an additional $1.7 \mathrm{mg}$ of water available. If the larva were able to retain and utilize water only as efficiently as a larva on the high-water diet (Case 1 ), that is if it retained only $41.9 \%$ of the water it gained and synthesized only $0.135 \mathrm{mg}$ of new tissue per $\mathrm{mg}$ of water available, it would synthesize only $6.5 \mathrm{mg}$ (dry wt) of new tissue and would have an efficiency of conversion of digested food of only $18.7 \%$. If the larva were able to retain $49.4 \%$ of the total water input, but was still able to synthesize only $0.135 \mathrm{mg}$ of new tissue per $\mathrm{mg}$ of water available (Case 2), it would synthesize $7.7 \mathrm{mg}$ of new tissue and would have a slightly higher efficiency of conversion of $22.1 \%$. If the larva were able to retain only $41.9 \%$ of the water it gained but could synthesize $0.230 \mathrm{mg}$ of new tissue per $\mathrm{mg}$ of water available (Case 3), it could synthesize $12.1 \mathrm{mg}$ of new tissue and would have an efficiency of conversion of $34.9 \%$. Finally, if the larva both retained and utilized water with the efficiency of a larva on the low-water diet (Case 4), it could synthesize $14.3 \mathrm{mg}$ of new tissue and would have an efficiency of conversion of $41.2 \%$. This hypothetical value, which is derived from the water budget, agrees very well with the experimental value of $40.9 \%$ (Table 1 ) which was derived from a dry weight growth budget.

These calculations illustrate that efficiency of conversion of digested food and growth are highly dependent upon the efficiency with which larvae retain water and the ability of the larvae to tolerate a decrease in tissue hydration level when confronted with a low-water diet. These capabilities are clearly adaptive mechanisms which enhance the retention and use of a potentially growth-limiting nutrient. We conclude, therefore, that nutrient limitation, rather than a high processing cost, is responsible for the reduced growth of herbivorous lepidopteran larvae on diets low in water.

Acknowledgements-We thank the National Science Foundation for a grant (BSR-8421268) to M.M.M., which supported this research. We thank D. Karowe and S. Reynolds for valuable criticisms, R. Kushler for help in statistical analyses, and S. Reynolds for sharing unpublished data with us.

\section{REFERENCES}

Aidley D. J. (1976) Increase in respiratory rate during feeding in larvae of the armyworm, Spodoptera exempta. Physiol. Ent. 1, 73-75.

Bhattacharya A. K. and Waldbauer G. P. (1969) Quantitative determination of uric acid in insect feces by lithium carbonate extraction and the enzymatic- 
spectrophotometric method. Ann. ent. Soc. Am. 62, 925-927.

Bursell E. (1967) The excretion of nitrogen in insects. $A d v$. Insect Physiol. 4, 33-67.

Lehninger A. L. (1975) Biochemistry: The Molecular Basis of Cell Structure and Function, 2nd edn. Worth Publish. ers, NY.

McEvoy P. B. (1985) Balancing insect energy budgets. Oecologia 66, 154-156.

McEvoy P. B. (1984) Increase in respiratory rate during feeding in larvae of the cinnabar moth Tyria jacobaeae. Physiol. Ent. 9, 191-195.

Phillips J. E., Hanrahan J., Chamberlin M. and Thomson B. (1986) Mechanisms of resorption in insect hindgut. Adv. Insect Physiol. 19, 329-422.

Powning R. F. (1953) Studies on the digestion of wool by insects. VIII. The significance of certain excretory products of the clothes moth, Tineola bisselliella, and the carpet beetle Attagenus piceus. Aust. J. biol. Sci. 6, 109-117.

Pramila M. and R. V. Krishnamoorthy (1977) Purine metabolite levels in the larval excreta of silkworm Bombyx mori L. Entomon 2, 1-5.

Reese J. C. and Beck S. D. (1978) Inter-relationships of nutritional indices and dietary moisture in the black cutworm (Agrotis ipsilon) digestive efficiency. J. Insect Physiol. 24, 473-479.

Reynolds S. E., Nottingham S. F. and Stephens A. E. (1985) Food and water economy and its relation to growth in fifth-instar larvae of the tobacco hornworm, Manduca sexta. J. Insect Physiol. 31, 119-127.

Reynolds S. E., Yeomans M. R. and Timmins W. A. (1986) The feeding behavior of caterpillars (Manduca sexta) on tobacco and on artificial diet. Physiol. Ent. 11, 39-51.
Schmidt D. J. and Reese J. C. (1986) Sources of error in nutritional index studies of insects on artificial diets. $J$. Insect Physiol. 32, 193-198.

Schroeder L. A. (1976) Energy, matter and nitrogen utilization by the larvae of the monarch butterfly Danaus plexippus. Oikos 27, 259-264.

Schroeder L. A. (1986) Protein limitation of a tree feeding Lepidopteran. Entomologia exp. appl. 41, 115-120.

Schroeder L. A. and Malmer M. (1980) Dry matter, energy and nitrogen conversion by Lepidoptera and Hymenoptera larvae fed leaves of black cherry. Oecologia 45, 63-71.

Scriber J. M. (1977) Limiting effects of low leaf water content on the nitrogen utilization, energy budget and larval growth of Hyalophora cecropia (Lepidoptera:Saturniidae). Oecologia 28, 269-287.

Scriber J. M. and Feeny P. (1979) The growth of herbivorous caterpillars in relation to degree of specialization and to growth form of food plants. Ecology 60, 829-850.

Slansky F. Jr and Scriber J. M. (1985) Food consumption and utilization. In Comparative Insect Physiology Biochemistry and Pharmacology (Ed. by Kerkut G. A. and Gilbert L. I.), Vol. 4, pp. 87-163. Pergamon Press, Oxford.

Timmins W. A., Bellward K., Stamp A. J. and Reynolds S. E. (1988) Food intake, conversion efficiency, and feeding behavior of tobacco hornworm caterpillars given artificial diet of varying nutrient and water content. Physiol. Ent. In press.

Waldbauer G. P. (1968) The consumption and utilization of food by insects. Adv. Insect Physiol. 5, 229-288.

Wrightman J. A. (1981) Why insect energy budgets do not balance. Oecologia 50, 166-169. 